Çukurova Üniversitesi Mühendislik Mimarlık Fakültesi Dergisi, 35(3), ss. 783-795, Eylül 2020

\title{
Killi Zeminlerin Donma-Çözülme Davranışlarında Cam Atık Çamurunun Etkisi
}

\author{
Barış MAHMUTLUOĞLU ${ }^{1}$, Baki BAĞRIAÇIK ${ }^{* 2}$ \\ ${ }^{1}$ Mersin Üniversitesi, Teknik Bilimler Meslek Yüksekokulu, İnşaat Bölümü, Mersin \\ ${ }^{2}$ Çukurova Üniversitesi, Mühendislik Fakültesi, İnşaat Mühendisliği Bölümü, Adana
}

Geliş tarihi: 22.09.2020 Kabul tarihi: 23.10.2020

$\ddot{\mathbf{O z}}$

Son yıllarda, atık malzemelerin ekosistem için ciddi bir tehlike oluşturması sebebiyle, birçok sektör, bu malzemelerin farklı alanlarda kullanılabilirliğini sorgulamaya başlamıştır. Bu bağlamda, araştırmacılar, atıkların zemin iyileştirme uygulamalarında da değerlendirilebileceğini, yapmış oldukları çalışmalarla vurgulamışlardır. Cam atık çamuru $(\mathrm{CAÇ})$ ise, cam üretimi için kullanılan hammaddenin işlenmesi sırasında ortaya çıkan bir atıktır. Bu atık, doğada ciddi miktarlarda birikmektedir. Literatürde, bu atığın kullanılmasına yönelik çalışmalar çok kısıtlıdır. Bu çalışmada ise, cam atık çamuru (CAÇ) ve çimentonun (ÇMT), kil bir zeminin dayanım ve konsolidasyon parametrelerine etkisi, donma-çözülme davranış1 altında araştırılmıştır. Donma-çözülme etkisi altında, CAÇ ilavesiyle, kil zeminin daha kararlı bir hale geldiği, zeminin dayanım parametrelerinin arttığı ve konsolidasyon davranışlarında ise iyileşmelerin olduğu gözlenmiştir. Buna ilaveten, çimento eklenmesi ile de, bu iyileşmelerin daha da arttı̆̆ görülmüştür.

Anahtar Kelimeler: Zemin iyileştirme, Cam atık çamuru, Donma-çözülme, Serbest Basınç Mukavemeti, Konsolidasyon

\section{Effect of Glass Waste Sludge on the Freezing-Thawing Behavior of Clayey Soils}

\begin{abstract}
In recent years, since waste materials constitute a serious degree of hazard to the eco-system, several sectors have started to question the usability of these materials in different fields. In this regard, researchers have pointed out by means of the performed studies that wastes can also be utilized in soil improvement applications. Glass waste sludge (GWS) is a waste generated during the processing of the raw material used for glass production. This waste accumulates in serious amounts in nature. Studies on the use of this waste are very limited in the literature. In this study, the effect of glass waste sludge (GWS) and cement (CMT) on the strength and consolidation parameters of a clay soil was investigated under freeze-thaw behavior. Under the effect of freezing-thawing, with the addition of GWS, the clay soil
\end{abstract}

"Sorumlu yazar (Corresponding author): Baki BAĞRIAÇIK, bbagriacik@ @u.edu.tr 
became more stable, strength parameters increased and consolidation behavior improved. In addition, these improvements have been found to be further enhanced by the addition of cement.

Keywords: Soil improvement, Glass waste sludge, Freezing-thawing, Unconfined compressive strength, Consolidation

\section{GíRiş}

Son yıllarda, atık malzemelerin bertaraf edilmeleri önemli gündem maddelerinden biri haline gelmiş durumdadır. Çevresel koruma, atık malzemelerin depolanması, dönüştürülmesi, imha edilmesi ve vergi masrafları bu atıklarla ilgilenmenin önemini gözler önüne sermektedir [1-5]. Bu sebeplerle, birçok sektör, ekosistemin kirlenmesini engellemek ve ilgili ağır vergi ve ücretleri düşürerek ekonomiyi canlandırmak adına, bu malzemeleri kendi bünyelerinde kullanma yoluna gitmeye başlamışlardır. Geoteknik mühendisleri, atık malzemelerin zemin iyileştirme çalışmalarında kullanılabilirliğini sürekli sorgulamakta, bu malzemelerin geleneksel güçlendirme katkılarının yerine geçebilme durumlarını sürekli irdelemektedirler. $\mathrm{Bu}$ bağlamda, birçok atık malzemenin gerek tek başlarına gerekse diğer atık malzemeler ile kullanımının, zeminlerin yükler altındaki davranışlarını nasıl etkileyeceğini araştırmaktadırlar. Böylece, hem bu atık malzemelerin ekosisteme zararları indirgenmiş, hem de pahalı kimyasal katkı malzemelerinin karışımlardaki oranları düşürülmüş olacağı için ekonomik bağlamda da ciddi bir gelişme kaydedilmiş olacaktır.

Zemin iyileştirme çalışmaları kapsamında, birçok araştırmacı, atık malzemelerin zeminlerde kullanılabilme potansiyellerini araştırmışlardır. Örneğin, Lin ve arkadaşları [6] tarafından, atık su arıtma çamuru külü ve uçucu külün, yumuşak killi zeminlerin iyileştirilme çalışmalarında değerlendirilebileceği deneysel olarak ispatlanmıştır. Ayrıca, atık su arıtma çamuru külünün, uçucu küle alternatif bir atık malzeme olduğu gösterilmiştir. Ayodele ve arkadaşları [7] ile Zhan ve arkadaşları [8], yürütmüş oldukları çalışmalarda, zeminlerin mukavemet parametrelerinin, atık su arıtma çamuru eklenmek suretiyle dikkat çekici şekilde iyileştirilebildiğini gözlemlemişlerdir. Başka bir deneysel çalışmada, taban külü olarak bilinen başka bir atık malzeme, Güllü [9] tarafından, ince daneli zeminlere farklı oranlarda eklenmiş ve ilgili zeminlerin serbest basınç mukavemeti, şekil değiştirme oranı, elastiktik özellikleri ve enerji emme kapasitelerinin ne derece etkilendiği araştırılmıştır. Çalışma sonunda, \%30 atık eklenmesi durumunda en iyi sonuçların elde edildiği ifade edilmiştir. Ayininuola ve Ayodeji [10] tarafından, \%7 oranında atık su çamuru külünün zeminlere ilave edilmesinin, çimentolaşma etkisi oluşturarak zemin tanelerini birbirlerine bağladığı ve bu şekilde zeminlerin kesme mukavemet parametrelerinin iyileştirilebildiği gösterilmiştir. Fauzi ve arkadaşları [11] tarafından, killi zeminlere, plastik yüksek yoğunluklu polietilen atıklar ile kırılmış cam parçaları karıştırılmıştır. Çalışma sonunda, karışımlardaki atık yüzdeleri arttırıldıkça, numunelerin CBR değerlerinin yükseldiği belirlenmiştir. Şeker kamışı küspesi külü ve sönmüş kireç, Hasan ve arkadaşları [12] tarafından, karayolu temel-altı zemini stabilizasyonunda değerlendirilmiş ve zeminin mukavemet değerlerinin iyileştiği saptanmıştır. Brooks [13] tarafından yürütülen bir çalışmada, zemin örneklerine uçucu kül ve misır külü ilave edilmiş ve numunelerin mukavemet değerlerinde yükselmeler olduğu belirlenmiştir. Ramakrishna ve Pradeepkumar [14] tarafından gerçekleştirilen bir çalışmada, zemin örneklerine çimento ile pirinç kabuğu eklenmiştir. Sonuçta, zeminlerin serbest basınç mukavemeti, CBR, plastiklik özellikleri iyi yönde değişirken bu tür atıkların kullanımının, ilgili uygulamaların ekonomilerini de iyileştirilebileceği ifade edilmiştir. Kireç, kalsiyum klorür ve pirinç kabuğu külü, Sharma ve arkadaşları [15] ile Ramakrishna ve Pradeepkumar [14] tarafından killi zeminlerin stabilizasyonunda kullanılmış ve olumlu sonuçlar elde edilmiştir. Başka bir katkı maddesi olan obsidyenin farklı sektörlerde kullanılması ile de birçok araştırmacı tarafından çalışmalar yürütülmüştür [16-18]. 
Volkanik bir kayaç türü olan obsidyen, zeminlerin iyileştirilmesinde de yaygınca kullanılmaktadır $[19,20]$. Ustabaş ve Kaya [3], bu malzemenin, çimento içerisinde puzzolan bir malzeme olarak kullanılabileceğini belirtmişlerdir. Urhan [2] tarafından, bünyesinde obsidyen bulunduran perlitin, sık ve düzenli atom örgüleri içeren bir yapıya sahip olması nedeniyle, çözünme etkilerine karşı dirençli olduğu ifade edilmiştir. Uçucu kül bazlı jeopolimerlerin, yüksek mukavemet ve termal dirençlilik ile düşük büzülme özelliklerine sahip oldukları da çalışmalarda gösterilmiştir [21]. Benzer çalışmalara ilgili literatürde sıklıkla rastlanılmaktadır. Örnek vermek gerekirse, kireç [22,23], uçucu kül [24-26], firın dişıkları [27], pirinç kabuğu [28], sığır kazeini [29], bioyakıt silisi [30], mermer tozu ve atığ $[31,32]$, kenaf lifi [33], kiremit tozu [34] gibi atıklar, zeminlere karıştırılmış ve sonuçlar gözler önüne serilmiştir. Son yıllarda gerçekleştirilen bazı çalışmalara bakılmak istenirse, zemin numunelerine, Abbaspour ve arkadaşları [35] tarafından atık lastik tekstil liflerinin değişen oranlarda eklenmesi, Liu ve arkadaşları [36] tarafından çimento, pirinç kabuğu külü ve kalsiyum karbür artığ malzemelerinin karıştırılması, Shah ve arkadaşları [37] tarafından alüminyumlu kimyasal bir bileşiğin hidratlaştırılmış çift sülfat tuzlarını içeren bir tür atık su arıtma çamurunun $\% 8$ oranında şap çamuru ile güçlendirilerek karıştırılması ile Taki ve arkadaşları [38] tarafından kireçle stabilize edilmiş atık çamuru malzemesinin eklenmesi gibi çalışmalara rastlanılabilir. Zemin iyileştirme çalışmalarında hem doğal malzemeler (Hindistan cevizi lifi, palmiye ağacı lifi, keten tohumu, şeker kamışı, tavuk kanadı gibi) hem de bazı kimyasal katkılar ile sentetik fiber malzemeler (Polyester, polietilen, cam, naylon, çelik tel, atık lastik gibi) kullanılmaktadır [1,39]. Akbulut ve arkadaşları [40], Chauhan [39], Demir ve arkadaşları [41], Ghazavi ve Roustaie [42], Gullu ve Hazirbaba [43], Hejazi ve arkadaşları [1], Jafari ve EsnaAshari [44], Yarbaşı ve arkadaşları [4], Yarbaşı [45], Kalkan [46], Kalkan [47], Zaimoğlu [48], Zorluer ve Demirbaş [49] tarafından gerçekleştirilmiş olan çalışmalarda, bahis konusu katkı malzemelerinin kullanılmasının, tüm zemin türlerinin geoteknik özelliklerinde olumlu iyileştirmeler sağlamanın yanı sıra, ekonomi ve çevre koruma gibi önemli alanlarda da kayda değer gelişmeler sağladığı vurgulanmıştır. Bu amaçlar doğrultusunda yürütülen uygulamalarda, zeminlerin donma-çözülme olayları sonrasında taşıma kapasitelerini arttırmak, yanal deformasyon ve oturma miktarlarını düşürmek amacıyla katkılar ve atıklardan yararlanılmaktadır [4,40,42,44,45,47, 50-52]. Özellikle iklimsel değişikliklerin etkili olduğu bölgelerde, zemin boşluklarında yer alan suyun bu olaylar neticesinde donmasi ve çözülmesi ciddi hacimsel deformasyonlara sebep olmakta ve yapılarda hasarların oluşmasına yol açarak yapı kullanım ömürlerini kısaltmaktadır. Akbulut ve arkadaşları [40] tarafından gerçekleştirilen bir çalışmada, sentetik fiber ve atık lastik kullanılarak, ince taneli zeminler başarılı bir şekilde iyileştirilmiştir. Kalkan [46] tarafından, ince daneli zeminlere silis dumanı katılması ardından donma-çözülme mukavemetlerinde artışlar olduğu gözlemlenmiştir. Ghazavi ve Roustaie [42] tarafından yürütülen başka bir çalışmada ise, ince daneli zeminler, fiber kullanılarak güçlendirilmeye çalışılmış ve serbest basınç mukavemetlerinde, donma-çözülme sonrası azalmalar kaydedilmiştir. Mermer tozunun, zeminlerin serbest basınç mukavemetlerini yükselttiği, Demir ve arkadaşları [41] ile Zorluer ve Demirbaş [49] tarafından yürütülen çalışmalarda tespit edilmiştir. Donma-çözülme olayları esnasında zemin danelerinin dizilimlerinde meydana gelen değişimlerin, bu zeminlerin mukavemet, permeabilite, durabilite ve sıkışabilirlik gibi fiziksel ve mekanik özelliklerinde değişikliklere yol açtığı, Andersland ve Ladanyi [53], Simonsen ve Isacsson [54], Yarbaşı ve arkadaşları [4], Wang ve arkadaşları [55], Qi ve arkadaşları [56], Güllü ve Hazırbaba [43], Ghazavi ve Roustaie [42] ve Zaimoğlu [48] gibi araştırmacıların yürüttüğü çalışmalarda gözler önüne serilmiştir. Ek olarak, donma neticesinde ortaya çıkan donma-kabarma durumları, zeminlerin bünyesinde yapısal hasarlar oluşturmakta ve zemin yüzeylerinde kalıcı deformasyonlara yol açmaktadır. Bahsi geçen sebepler doğrultusunda, ince dane oranı, sürşarj yükü, iklim şartları ile ortamda su bulunması gibi donma kabarmasını etkileyen unsurlar, Tester ve Gaskin [57], Hermansson [58], Konrad ve Lemieux [59], Hui ve Ping [60] ve Rempel [61] 
gibi araştırmacıların çalışmalarında sıklıkla yer almıştır. Bahsi geçen atık malzemelerin, ekosisteme birikme sonucu sebep olabilecekleri zararlı etkileri azaltmak ile bu malzemelerin beraberlerinde getirdiği bertaraf edilme, depolanma, geri dönüştürülme, ilgili ağır vergiler ve ücretler gibi unsurlarını olumlu yönde geliştirmek, bahsi geçen çalışmaların ortak ilgi alanları olmaktadır. Ayrıca, güçlendirme uygulamalarında kullanılan hem doğaya zararlı hem de pahalı kimyasal malzemelerin, kısmen ya da tamamen bu atı malzemeler ile değiştirilebilecek durumda olması, birçok sektörde olduğu gibi, geoteknik mühendisliğinde de atıkları gittikçe daha fazla ilgi çekici hale getirmektedir. Yürütülmüş olan bu çalışma, yukarda bahsedilenlere benzer fakat ilgili literatür kapsamında daha önce değerlendirilmemiş bir tür atığı kapsamaktadır. Söz konusu atık, cam üretim fabrikalarının bir ön-atığı olup, sürekli ciddi miktarlarda doğaya boşaltılmakta ve önemli derecede çevre kirliliğine sebep olmaktadır. Bu atık malzeme, cam malzemesinin elde edilebilmesi için gerekli olan mineralojik kısım, ilgili madenden çıkartılmış olan malzemeden ayrıştırıldıktan sonra ortaya çıkmaktadır. Cam atık çamuru olarak geçen bu atık, bu çalışma kapsamında, ekosisteme katkı sağlamak ve bahsi geçen yararlı etkileri sağlayabilmek gibi konularda değerlendirilmiş ve elde edilen sonuçlar yorumlanmıştır. $\mathrm{Bu}$ atığın, killi zeminler için büyük bir sorun olan donma-çözülme problemlerinin giderilmesinde etkisi olup olmadığı, killi zemin numunelerine belli oranlarda karıştırılıp bir dizi deneye tabi tutularak irdelenmiştir. Elde edilen ilişkiler ayrıntılı bir şekilde analiz edilmiş ve sonuçlar grafikler, çizelgeler ve yorumlarla gözler önüne serilmiştir.

\section{MATERYAL VE METOT}

\subsection{Materyal}

Çalışma kapsamında yürütülen deneylerde kullanılan killi zemin numuneleri Adana'dan ve cam üretim prosesi sonrasında ortaya çıkan cam atık çamuru (CAÇ) ise, Mersin-Adana yolu üzerinde bulunan bir cam fabrikasından temin edilmiştir (Şekil 1). Malzemeler üzerinde, öncelikle elek analizi deneyleri gerçekleştirilmiştir. Elde edilen deney sonuçları, Şekil 2'de gradasyon eğrileri olarak verilmiştir. Sonrasında, malzemelerin endeks özellikleri belirlenmiştir. Killi zemin numunelerinin dane birim hacim ağırlık değeri $27 \mathrm{kN} / \mathrm{m}^{3}$ olarak saptanmıştır. Optimum su muhtevası ve maksimum kuru birim hacim ağırlık değerleri ise, sırasıyla, \%18 ve $17,40 \mathrm{kN} / \mathrm{m}^{3}$ olarak bulunmuştur. Killi zeminin sinıfı ise, TS 1500 [62] referans alınarak, "orta plastisiteli kil" olarak belirlenmiştir. Kil zemin için yapılan analizlerde, zeminin kuvars, kalsit ve kil grubu mineraller (kaolinit, simektit ve vermikülit) içerdiği görülmüştür. Ayrıca, kullanılan cam atık çamurunun dane birim hacim ağırlığ $27,6 \mathrm{kN} / \mathrm{m}^{3}$ olarak saptanmıştır.

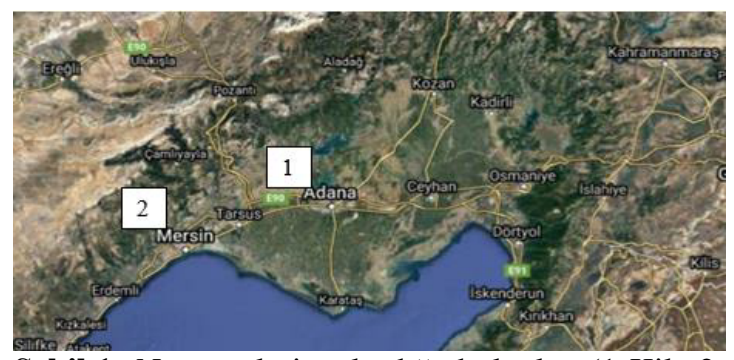

Şekil 1. Numunelerin alındığı bölgeler (1-Kil, 2Cam atığ 1 )

Killi zemin numunelerinin ve cam atığının kimyasal içerikleri, Panalytical marka X-Ray Fluoresence (XRF) cihazı kullanılarak belirlenmiş ve numunelerin kimyasal içerikleri Çizelge 1'de verilmiştir.

Çizelge 1. Kil (KZ) ve cam atı̆̆ının (CAÇ) kimyasal içerikleri

\begin{tabular}{|c|c|c|}
\hline İçerik (\%) & KZ & ÇAÇ \\
\hline $\mathrm{MgO}$ & 6,1 & 6,49 \\
\hline $\mathrm{Al}_{2} \mathrm{O}_{3}$ & 18,4 & 8,24 \\
\hline $\mathrm{SiO}_{2}$ & 50,6 & 18,65 \\
\hline $\mathrm{P}_{2} \mathrm{O}_{5}$ & 0,65 & 8,73 \\
\hline $\mathrm{K}_{2} \mathrm{O}$ & 3,10 & 8,31 \\
\hline $\mathrm{CaO}$ & 3,20 & 22,89 \\
\hline $\mathrm{MnO}$ & 3,10 & 9,65 \\
\hline $\mathrm{Fe}_{2} \mathrm{O}_{3}$ & 8,70 & 7,56 \\
\hline $\mathrm{Na}_{2} \mathrm{O}$ & 2,50 & 5,98 \\
\hline $\mathrm{TiO}_{2}$ & 1,65 & 3,50 \\
\hline $\mathrm{K}_{1} \mathrm{zd} \mathrm{rma} \mathrm{Kayb}$ & 3,15 & - \\
\hline
\end{tabular}




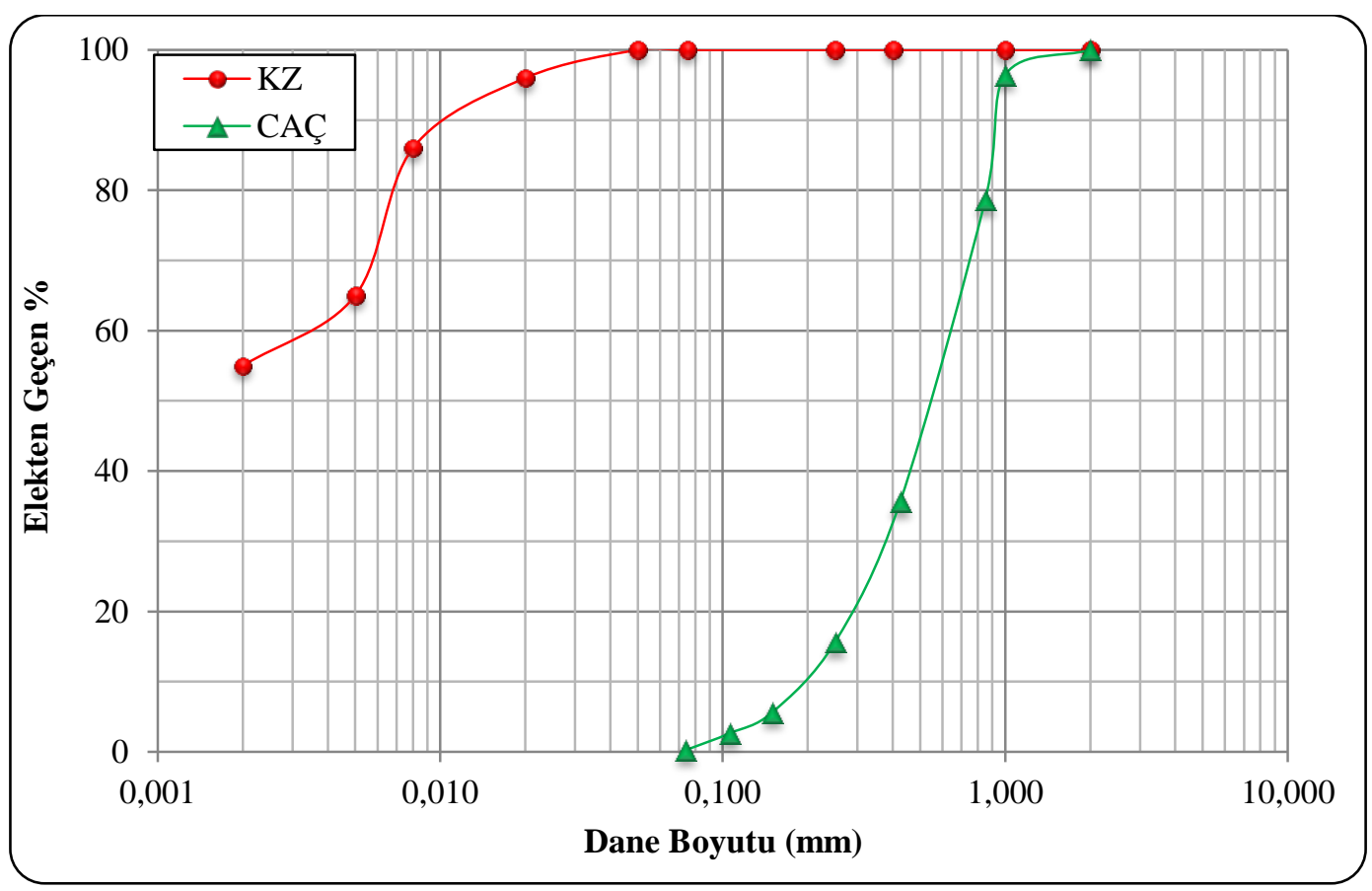

Şekil 2. Kil (KZ) ve cam atığının (CAÇ) dane çapı dağılım eğrileri

\subsection{Metot}

Çalışmada kullanılan numuneler, optimum su muhtevalarında ve belirlenen karışım oranlarında hazırlanarak, donma-çözülme etkilerine maruz bırakılmıştır. Numuneler, su muhtevalarında değişme olmaması için desikatörlerde bekletilmiştir. Çalışmada, donma-çözülme davranışı incelenirken, literatürdeki çalışmalardaki sıcaklık, zaman dilimi ve çevrim sayıları seçilmiştir [42,50,63,64]. Buna göre, donmaçözülme çevrim sayısı $1,3,5$ ve 10 , sicaklık değerleri donma için $-20{ }^{\circ} \mathrm{C}$ ve çözülme için $+25{ }^{\circ} \mathrm{C}$, her bir sicaklıkta bekleme süresi ise 6 saat olarak alınmıştır. Numuneler, donma-çözülme kabinine folyo ile sarılmış ve deney süresince donma-çözülme kabininden çıkarılmamıştır. Numuneler, donma-çözülme kabinine konulduktan sonra, ilk olarak $-20{ }^{\circ} \mathrm{C}^{\prime}$ ye getirilerek 6 saat beklenmiş ve sonrasında $+25{ }^{\circ} \mathrm{C}^{\prime}$ ye getirilerek 6 saat daha beklenmiştir. 12 saatin sonunda tamamlanan bu işlem ise 1 çevrim olarak kabul edilmiştir [42,50]. Çevrimler sonunda, ilgili numuneler ile mukavemet ve konsolidasyon deneyleri yapılmıştır.
Kil zemine karıștırılan CAÇ oranlar1 $\% 5, \% 10, \% 15, \% 20, \% 25, \% 30$ olarak seçilirken, Çimento (ÇMT) oranları \%2, \%4, \%6 ve $\% 8$ olarak alınmıştır. Serbest basınç deneylerinde, her karışım oranı için, optimum su muhtevasında hazırlanan kohezyonlu zemin numuneleri, $50 \mathrm{~mm}$ çapında, boyu çapının iki katı, doygun ve kılcal çatlak içermeyecek şekilde hazırlanmıştır [65]. Zemin numunesi, iki parçalı kalıp yağlandıktan sonra çelik tüpe yerleştirilmiştir. Kalıbın iki ağzından taşan zemin numunesi, kıl testereyle kesilip atılmıştır. Oluşturulan deney numuneleri, serbest basınç deneyine tabi tutularak dayanımlar belirlenmiştir. Deneylerde, zemin numunesi, presin alt platformuna merkezlenerek oturtulduktan sonra, üst başlık numune üst yüzeyine rahatça ve tam değecek şekilde indirilmiş ve bu işlemler ilgili standartta belirtildiği şekilde gerçekleştirilmiştir [65]. Boy değişimini ölçen komparatör saati, alt ve üst başlıklar arasına yerleştirilerek sıfırlanmıştır. Yüklemeler, numunede dakikada \%0,5-\%2 aras1 birim boy kısalması oluşturacak şekilde, standartta belirtildiği gibi uygulanmıştır [65]. Sonuçta, 
taşıma güçleri belirlenirken, düşey yük-deplasman eğrilerinin pik yaptığı değerler alınmış ve bu pik değerlerin yarısı alınarak kohezyon değerleri belirlenmiştir. Ayrıca, konsolidasyon deneyleri, TS 1900-2'de [65] belirtildiği şekilde yürütülmüştür.

Konsolidasyon deneyi yapilacak olan numuneler, $100 \mathrm{kPa}$ ön-konsolidasyon basınc1 altında önkonsolide edilen zeminden alınmış ve deneylerde iç çapı $50 \mathrm{~mm}$, yüksekliği $20 \mathrm{~mm}$ olan ringler kullanılmıştır. Konsolidasyon hücresi içerisine doldurulan sıv1, ön-konsolide edilen zemindeki karışım sıvısı ile aynı olacak şekilde hazırlanmıştır. Hücre içerisindeki sıvının buharlaşmasını önlemek için, hücrenin üst yüzeyi lastik bir kılıf ile kapatılmıștır. Hücre sıvısı içerisinde 1 gün süreyle bekletilerek doygun hale getirilen numunelerde, şişme basınçları ve zamana bağlı oturma değerleri hesaplanmıştır.

\section{BULGULAR ve TARTIŞMA}

\subsection{Optimum Su İçeriklerinin Belirlenmesi}

$\% 5, \% 10, \% 15, \% 20, \% 25$ ve $\% 30$ karışımları için optimum su miktarlarını belirlemek adına kompaksiyon deneyleri yapılmış ve sonuçları 3'te verilmiştir.

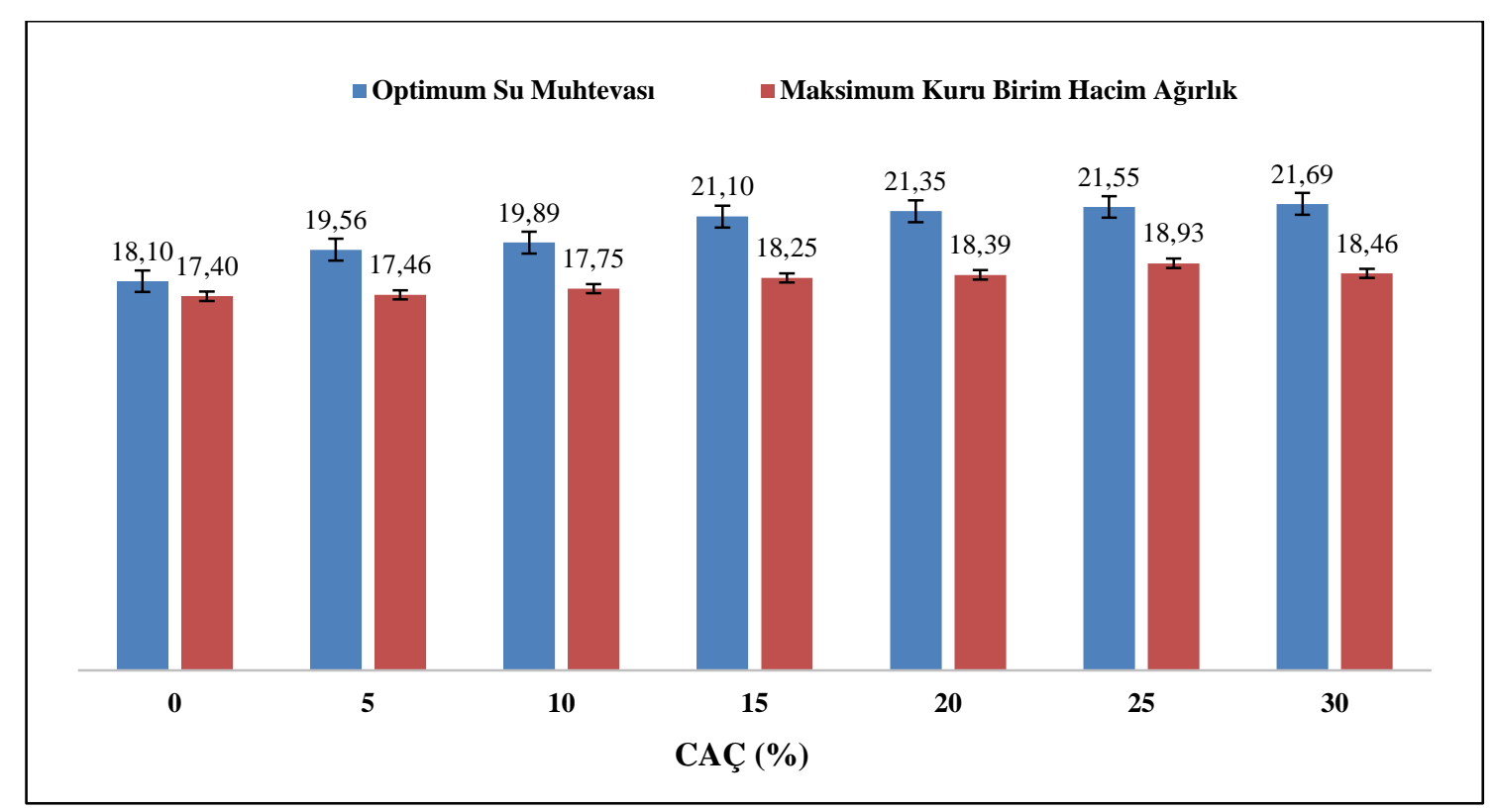

Şekil 3. Farklı CAÇ oranları için kompaksiyon deney sonuçları

\subsection{Mukavemet Parametrelerinin Belirlenmesi}

Sadece kil zemin, farklı oranlarda CAÇ eklenmiş kil zemin ve yine farklı oranlarda CAÇ-ÇMT eklenmiş kil zemin durumlarında, farklı döngüler için serbest basınç mukavemetleri belirlenmiş ve sonuçlar sırasıyla Şekil 4, Şekil 5 ve Şekil 6'da gösterilmiştir. Şekil 4'ten de görülebileceği gibi, sadece kil zemin olmasi durumunda, donmaçözülmede döngü sayısı arttıkça serbest basınç mukavemetlerinde azalmalar meydana gelmektedir. $\mathrm{Bu}$ aşamada, donma-çözülmenin, kil zeminin basınç dayanımı üzerine olumsuz bir etkiye sebep olduğu gözlemlenmiștir. Şekil 5'in incelenmesi ile CAÇ oranı arttıkça, serbest basınç dayanımlarının arttığı ve ancak artan donmaçözülme döngü sayısına bağlı olarak serbest basınç dayanımlarının yine azaldığı görülebilir. CAÇ ilavesi, donma-çözülme etkisinde, dayanımın iyileştirilmesinde kil zemini daha kararlı bir hale getirmiştir. Şekil 6'dan da gözlemlenebileceği gibi, kil zemin ve farklı CAÇ oranlarında hazırlanan 
numuneler, farklı oranlarda ÇMT ilave edilmesi ile donma-çözülme etkisi altında kayda değer oranlarda daha yüksek dayanımlar sergilemişlerdir. Buradan, kil zemine CAÇ ve ÇMT ilave edilmesinin, zeminin donma-çözülme etkisi altındaki davranışını ciddi derecelerde iyileştirdiği ifade edilmiştir.

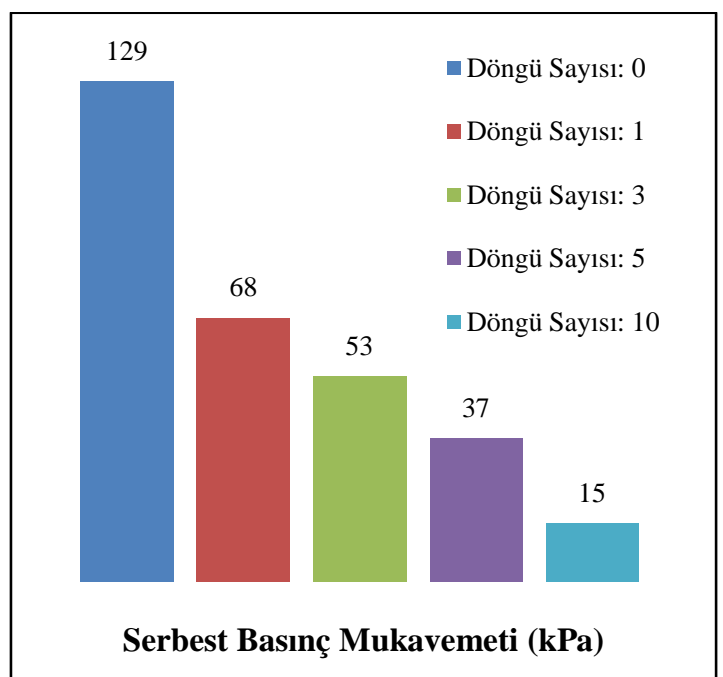

Şekil 4. Kil zeminin farklı döngüleri için serbest basınç mukavemetleri

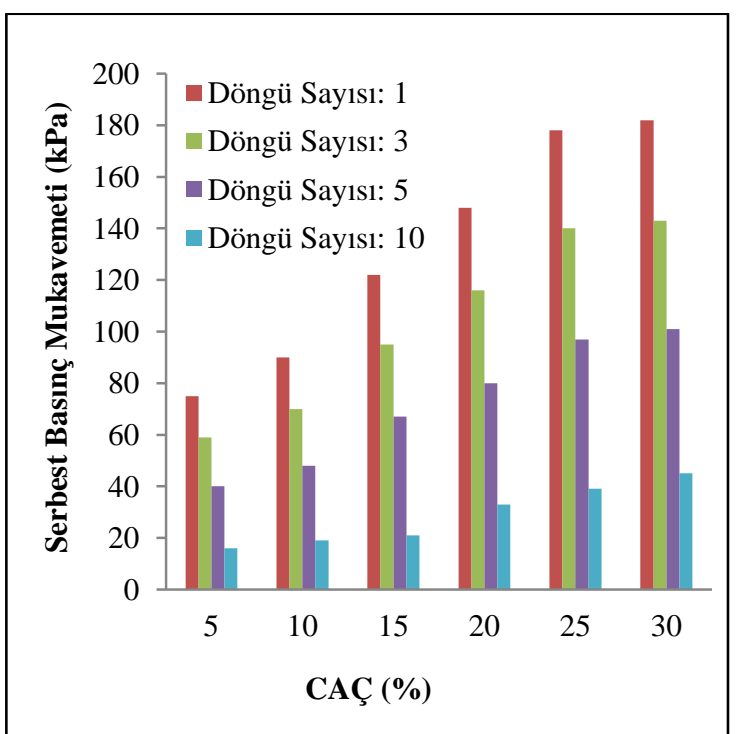

Şekil 5. Farklı CAÇ oranları ve farklı döngülerdeki numuneler için serbest basınç mukavemetleri

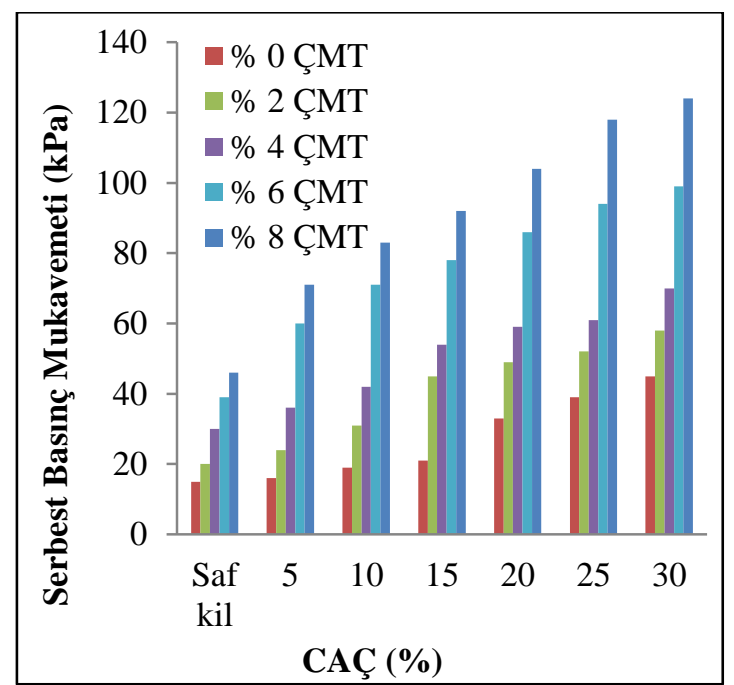

Şekil 6. Farklı CAÇ ve ÇMT oranları için serbest basınç mukavemetleri (Döngü sayısı:10)

\subsection{Karışımların Oturma Parametrelerinin Belirlenmesi}

Şekil 7, Şekil 8 ve Şekil 9'da sırasıyla, sadece kil zemin olması, zemine farklı oranlarda CAÇ katılması ve farklı oranlarda CAÇ-ÇMT katılması durumlarında, farklı döngüler için şişme basınçları görülmektedir. Sonuçlara göre, Şekil 7'den görülebileceği gibi, saf kil zemin olması durumunda, donma-çözülme döngü sayısının artmasına bağlı olarak şişme basınçlarının kayda değer bir şekilde arttığ 1 görülmüştür. Buradan, kil zeminin donma-çözülme etkisinde zayıf bir davranış sergilediği gözlemlenmiştir.

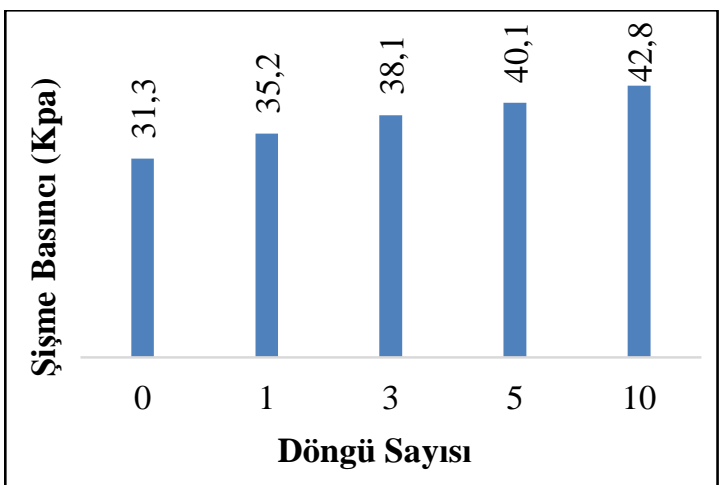

Şekil 7. Kil zeminin farklı döngü sayılarındaki şişme basınçları 
Aşağıda verilmiş olan Şekil 8'in incelenmesi ile de anlaşılabileceği gibi, kil zemine, artan oranlarda CAÇ eklenmesi halinde, aynı donma-çözülme döngülerinde şişme basınçlarının düştüğü belirlenmiştir. Ancak, donma-çözülme döngü sayıları arttıkça, karışımların şişme potansiyelinin de arttığı görülmüștür. Öte yandan, aşağıda verilmiş olan Şekil 9'da görülebileceği gibi, aynı donma-çözülme döngü sayısında, kil zemine farklı oranlarda CAÇ ve farklı oranlarda ÇMT eklenmesi durumlarında, numunelerin şişme potansiyellerinin kayda değer oranlarda düştüğü saptanmıştır.

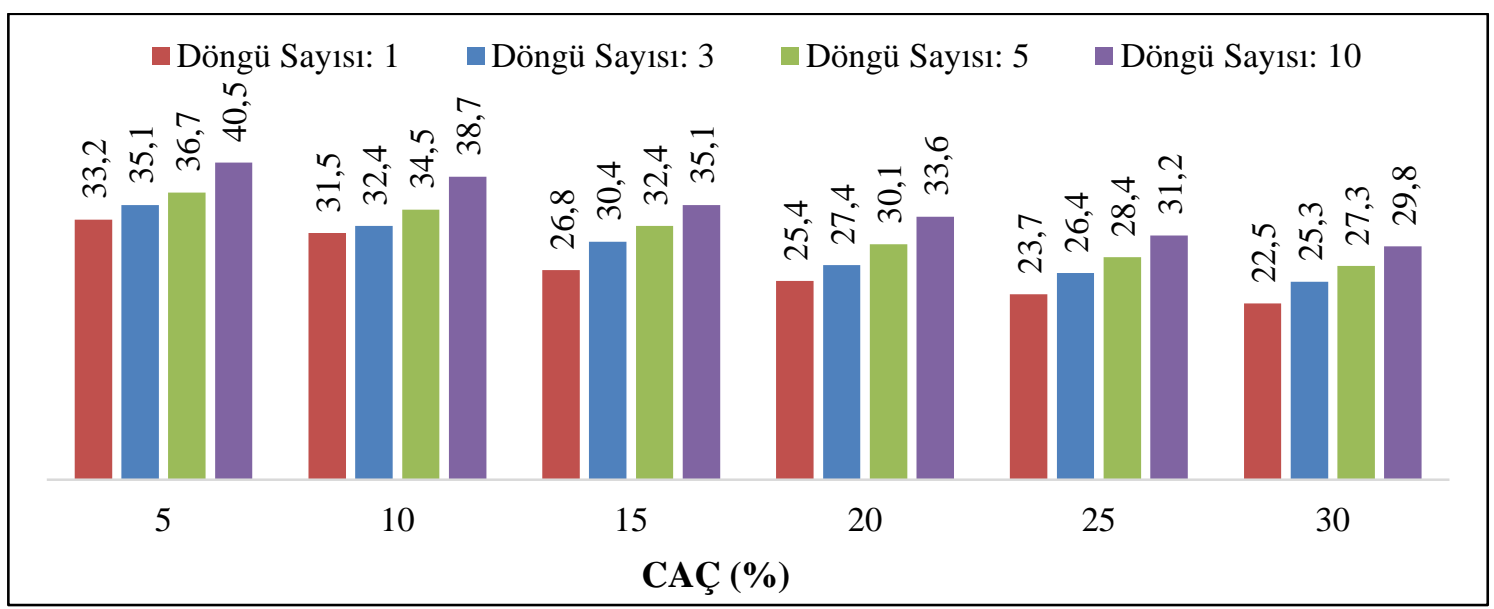

Şekil 8. Farklı döngü sayıları ve farklı CAÇ oranlarındaki numunelerin şişme basınçları

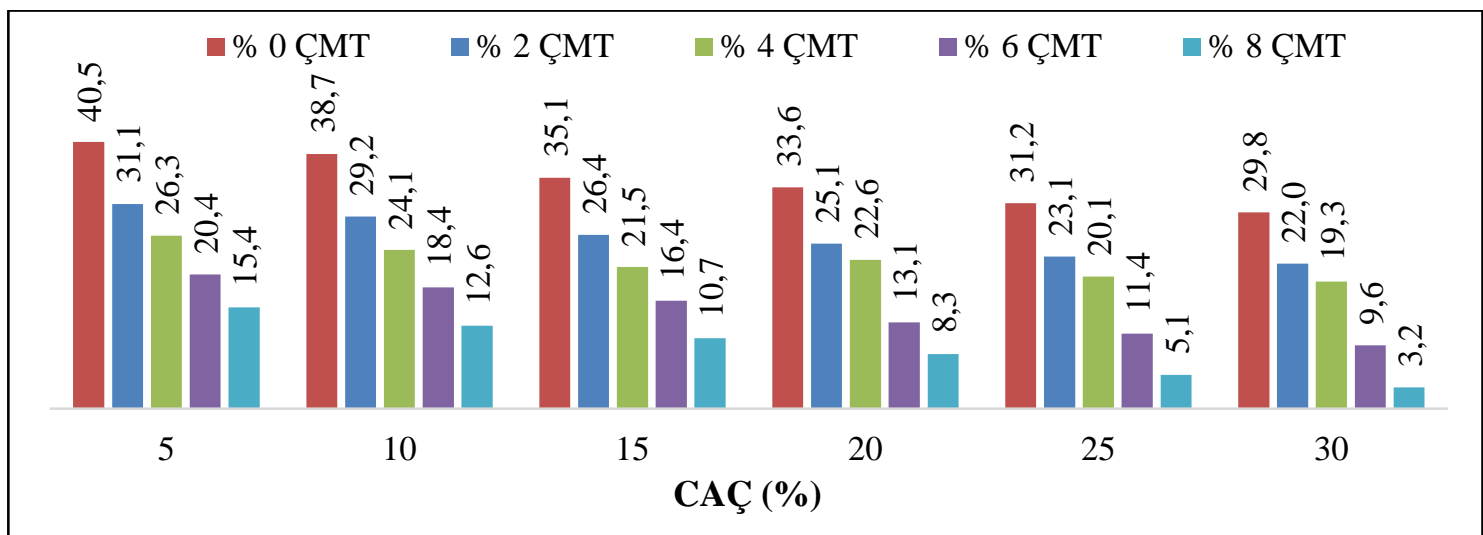

Şekil 9. Farklı CAÇ ve ÇMT oranlarındaki numunelerin şişme basınçları (Döngü sayısı:10)

Şekil 10 ve Şekil 11'de, sırasıyla, sadece kil zemin olması ve kil zemin-CAÇ-ÇMT karışımları olması durumlarında zamana bağlı oturma değerleri görülmektedir. Sonuçlara göre, Şekil 10'un incelenmesiyle görülebileceği gibi, donmaçözülme döngü sayıları arttıkça, saf kil zeminde konsolidasyon oturmalarının arttığı belirlenmiştir. Ancak, donma-çözülme sayısı 5, kadar, konsolidasyon oturmaları hızlı bir şekilde artarken, bu değerden sonra oturma değerlerinde kayda değer artmalar olmadığı saptanmıştır. Şekil 11'de ise, kil zemine CAÇ ilave edildiğinde, konsolidasyon oturmalarının, donma-çözülme etkisi altında saf kil zemine göre kayda değer bir oranda azaldığı görülmektedir. Ayrıca, kil zemine CAÇ'ye ek olarak ÇMT eklenmesi durumlarında ise, konsolidasyon oturmalarının $4 \mathrm{~mm}$ mertebelerinden 1,5 $\mathrm{mm}$ mertebelerine kadar azaldığı gözlemlenmiştir. 


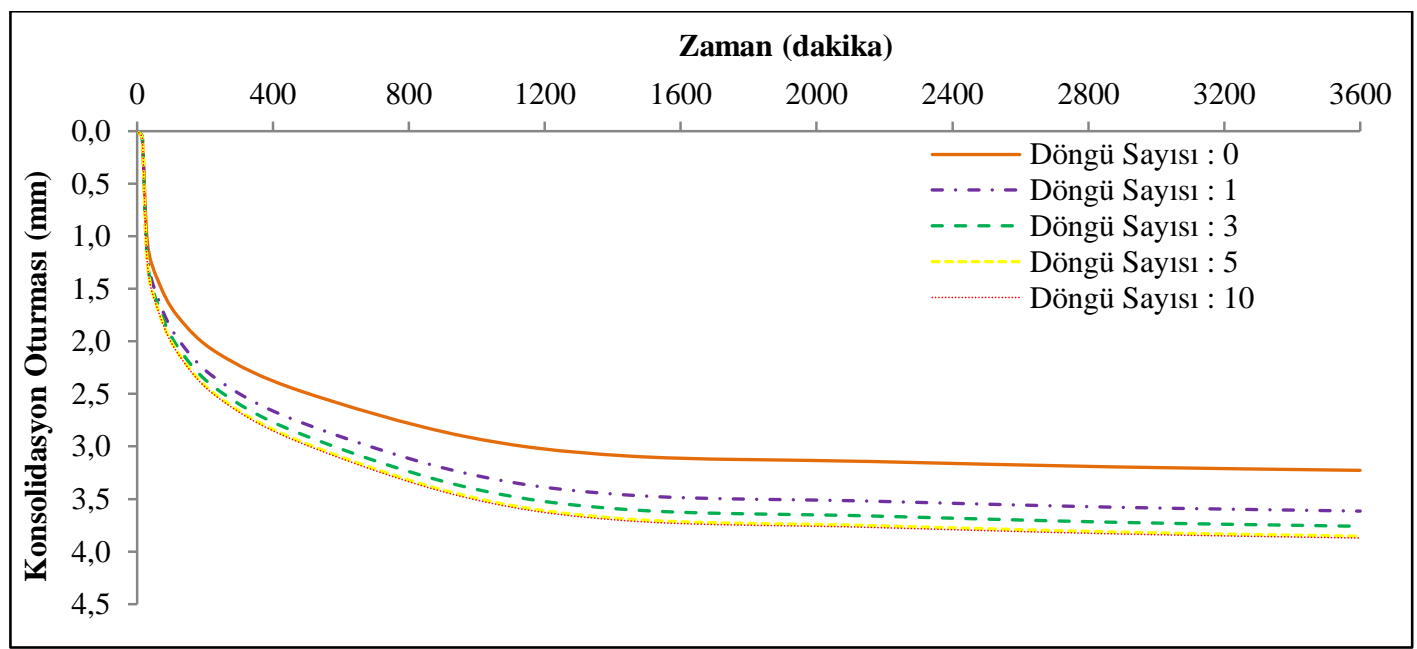

Şekil 10. Farklı döngü sayıları için konsolidasyon oturmaları

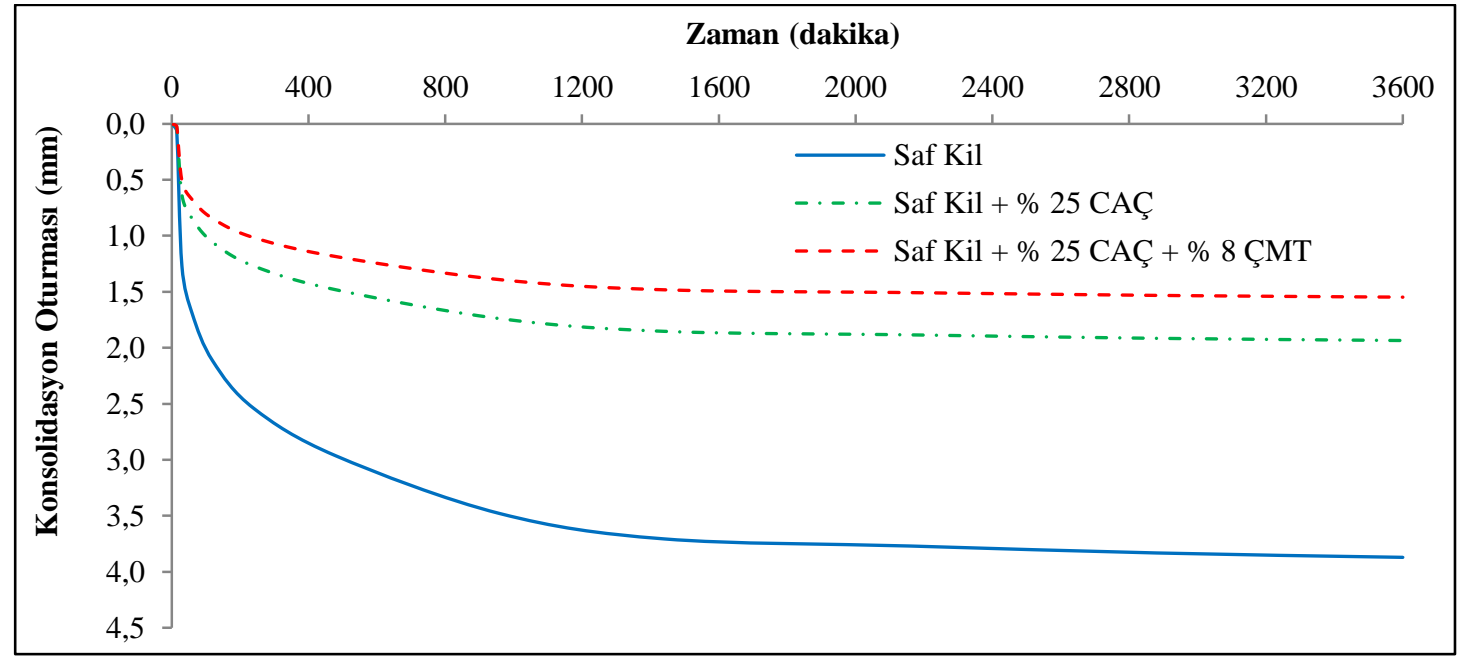

Şekil 11. Saf Kil, Kil+\%25 CAÇ ve Kil+\%25 CAÇ+\%8 ÇMT için konsolidasyon oturmaları (Döngü say1s1:10)

\section{SONUÇLAR}

$\mathrm{Bu}$ çalışmada, donma-çözülme etkisi altında, kil zemine CAÇ ve ÇMT eklenmesi durumlarında mukavemet, konsolidasyon ve şişme parametrelerinde meydana gelen değişimler araştırılmıştır. Elde edilen sonuçlar aşağıda özetlenmiştir.

- Kil zeminde, donma-çözülme döngü sayısı arttıkça, serbest basınç mukavemetlerinde azalmalar meydana geldiği gözlemlenmiştir. Şişme basınçlarının ise, donma-çözülme döngü sayısının artmasına bağlı olarak kayda değer oranlarda arttığı belirlenmiştir. Buradan, donma-çözülme davranışının, saf kil zeminin basınç dayanımı üzerinde olumsuz bir etkisi olduğu görülmüştür. Ayrıca, donma-çözülme döngü sayısı 5'e kadar, kil zeminde konsolidasyon oturmalarının arttığı, bu değerden sonra ise kayda değer artışların gerçekleşmediği belirlenmiştir. 
- CAÇ ilavesinin, donma-çözülme etkisinde, dayanımın iyileştirilmesinde kil zemini daha kararlı bir hale getirdiği ve böylece dayanımın arttığ belirlenmiştir. CAÇ eklenmesi halinde, aynı donma-çözülme döngülerinde, şişme basınçlarının düştüğü fakat donma-çözülme döngü sayıları arttıkça numunelerin şişme potansiyellerinin de arttığı belirlenmiştir. Kil zemine CAÇ ilave edildiğinde, konsolidasyon oturmalarının, donma-çözülme etkisi altında, saf kil zemine göre kayda değer oranlarda azaldığı gözlemlenmiştir.

- Kil zemine CAÇ ve ÇMT ilavesi ile, donmaçözülmeye maruz bırakılan numunelerde dayanımların kayda değer bir şekilde iyileştiği gözlemlenmiştir. Aynı donma-çözülme döngü sayısında, kil zemine farklı oranlarda CAÇ ve farklı oranlarda ÇMT eklenmesi durumlarında, numunelerin şişme potansiyellerinin ciddi oranlarda düştüğü görülmüştür. Ayrıca, kil zemine, CAÇ yanında ÇMT'de eklenmesi durumunda, konsolidasyon oturmalarının $4 \mathrm{~mm}$ mertebelerinden 1,5 $\mathrm{mm}$ mertebelerine kadar azaldığı gözlemlenmiştir.

- Bu çalışma sonucunda, donma-çözülme etkisi altında olan kil zeminlere CAÇ ve ÇMT eklenmesiyle, mukavemet, şişme ve konsolidasyon parametrelerinde kayda değer iyileşmelerin meydana geldiği belirlenmiştir.

\section{KAYNAKLAR}

1. Hejazi, S.M., Sheikhzadeh, M., Abtahi, S.M., Zadhoush, A., 2012. A Simple Review of Soil Reinforcment by Using Natural and Synthetic Fibers, Construction and Building Materials, $30,100-116$.

2. Urhan, S., 1991. Silisin Alkali Ortamda Çözünmesine Etki Eden Faktörler. Türkiye Çimento Müstahsilleri Birliği Çimento Bülteni, 28(286), 15-21.

3. Ustabaş, İ, Kaya, A., 2018. Comparing the Pozzolanic Activity Properties of Obsidian to Those of Fly Ash and Blast Furnace Slag.
Construction and Building Materials, 164, 297-307.

4. Yarbaşı, N., Kalkan, E., Akbulut, S., 2007. Modification of the Geotechnical Properties, as Influenced by Freeze-Thaw, of Granular Soils with Waste Additives, Cold Regions Science and Technology, 48, 44-54.

5. Yarbaş1, N., Alacalı, M., 2018. Atık Lastik Parçalarılya Güçlendirilmiş İri Taneli Zeminlerin Donma-çözülme Sonucu Mukavemetlerindeki Değişimin İncelenmesi. Pamukkale Univ. Müh Bil. Dergisi, 24(3), 561-565.

6. Lin, D.F., Lin, K.L., Luo, H.L., 2007. A Comparison Between Sludge Ash and Fly Ash on the Improvement in Soft Soil. J. Air Waste Manage, 57(1), 59-64.

7. Ayodele, A.L., Adebisi, A.O., Kareem, M.A., 2016. Use of Sludge Ash in Stabilising Two Tropical Laterite. Int. J. Sci. Eng. Res., 7.

8. Zhan, T.L., Zhan, X., Lin, W., Luo, X., Chen, Y., 2014. Field and Laboratory Investigation on Geotechnical Properties of Sewage Sludge Disposed in a Pit at Changan Landfill, Chengdu, China. Engineering geology, 170, 24-32.

9. Güllü, H., 2014. Factorial Experimental Approach for Effective Dosage Rate of Stabilizer: Application for Fine-grained Soil Treated with Bottom Ash. Soils and Foundations, 54(3), 462-477.

10. Ayininuola, G., Ayodeji, I., 2016. Influence of Sludge Ash on Soil Shear Strength. Journal of Civil Engineering Research, 6(3), 72-77.

11. Fauzi, A., Zuraidah, D., Usama, J.F., 2016. Soil Engineering Properties Improvement by Utilization of Cut Waste Plastic and Crushed Waste Glass as Additive. International Journal of Engineering and Technology, 8(1), 15. https://doi.org/10.7763/IJET.2016.V8.851.

12. Hasan, H., Dang, L, Khabbaz, H., Fatahi, B., Terzaghi, S., 2016. Remediation of Expansive Soils Using Agricultural Waste Bagasse Ash. Procedia Eng., 143, 1368-1375.

13. Brooks, R.M., 2019. Soil Stabilization with Fly Ash and Corn Waste Ash-improvements in Engineering Characteristics. Int. J. Appl. Eng. Res., 14(4), 1025-1030. 
14. Ramakrishna, A.N, Pradeepkumar, A.V., 2006. Stabilization of Black Cotton Soil Using Rice Husk Ash and Cement. In National Conference on Civil Engineering Meeting the Challenges of Tomorrow, GND Engineering College, Ludhiana, 215-220.

15. Sharma, R.S., Phanikumar, B.R., Rao, B.V., 2008. Engineering Behavior of a Remolded Expansive Clay Blended with Lime, Calcium Chloride and Rice-husk Ash. Jnl. of Mat. in Civil Eng, 20(8), 509-515.

16. Browna, F.H., Nash, B.P., Fernandez, D.P., Merrick, H.V., Thomas, R.J., 2013. Geochemical Composition of Source Obsidians from Kenya. Journal of Archaeological Science, 40, 3233-3251.

17. Campbell, S., Healey, E., 2016. Multiple Sources: The pXRF Analysis of Obsidian from Kenan Tepe, S.E. Turkey. Journal of Archaeological Science: Reports, 10, 377-389.

18. Carter, T., Poupeau, G., Bressy, C., Pearce, N.J.G., 2006. A New Programme of Obsidian Characterization at Çatalhöyük, Turkey. Journal of Archaeological Science, 33(7), 893-909.

19. Çolak, A., Aygün, H., 2011. Sarıkamış (Kars) Civarı Obsidyenleri Bilgi Notu. MTA Maden Etüt ve Arama Dairesi Başkanlığı, SERKA Raporu. Kars, Türkiye, 2011.

20. Ercan, T., Yegingil, Z., Bigazzi, G., 2016. Obsidian Definition and Characteristics, Distribution and Geochemical Characteristics of Those of the Central Anatolian Obsidian in Anatolia. Journal Geomorphol, 17(1989), 71-83.

21. Marjanovic, N., Komljenovic, M., Baščarevic, Z., Nikolic, V., Petrovic, R., 2015. Physicalmechanical and Microstructural Properties of Alkali-activated fly Ash-blast Furnace Slag Blends. Ceramics International. 41, 1421-1435.

22. Bell, F.G., 1996. Lime Stabilization of Clay Minerals and Soils. Engineering Geology, 42(4), 223-37. https://doi.org/10.1016/j.con buildmat.2018.03.049.

23. Mohd Yunus, N.Z., Wanatowski, D., Abdul Hassan, N., Marto, A., 2016. Shear Strength and Compressibility Behavior of Lime Treated Organic Clay. KSCE Journal of Civil
Engineering, KSCE, 20(5), 1721-1727. https://doi.org/10.1007/s12205-018-1294-X.

24. Arulrajah, A., Mohammadjavad, Y., Mahdi, M. D, Suksun, H., Myint, W.B., Melvyn, L., 2018. Evaluation of Fly Ash and Slag-based Geopolymers for the Improvement of a Soft Marine Clay by Deep Soil Mixing. Soils and Foundations, 58(6), 1358-70. https://doi.org/ 10.1016/j.sandf.2018.07.005.

25. Biradar, K.B., Arun, K.U., Satyanarayana, P.V.V., 2014. Influence of Steel Slag and Fly Ash on Strength Properties of Clayey Soil: A Comparative Study. International Journal of Engineering Trends and Technology (IJETT)(14) (2). https://doi.org/10.14445/22315381/ IJETT-V14P213.

26. Çokca, E., Yazici, V., Ozaydin, K., 2009. Stabilization of Expansive Clays Using Granulated Blast Furnace Slag (GBFS) and GBFS-cement. Geotech. Geol. Eng., 27(4), 489.

27. Kumar, A., Sivapullaiah, P.V., 2012. Improvement of Strength of Expansive Soil with Waste Granulated Blast Furnace Slag. In Geo Congress 2012: State of the Art and Practice in Geotechnical Engineering, 3920(8). https://doi.org/10.14445/22315381/IJETTV11P254.

28. Kumar, A., Gupta, D., 2016. Behavior of Cement-stabilized Fiber-reinforced Pond Ash, Rice Husk Ash-soil Mixtures. Geotextiles and Geomembranes, 44(3), 466-74. https://doi.org/ 10.1016/j.jrmge.2016.05.010.

29. Chang, I., Jooyoung, I., Moon-Kyung, C., GyeChun, C., 2018. Bovine Casein as a New Soil Strengthening Binder from Diary Wastes. Construction and Building Materials, 160, 1-9. https://doi.org/10.1016/j.conbuildmat.2017.11. 009.

30. Jin, L.M., MohdYunus, N.Z, Hezmi, M.A., Rashid, A.S.A., Marto, A., Kalatehjari, R., Pakir, F., Mashros, N., Ganiyu, A., 2018. Predicting the Effective Depth of Soil Stabilization for Marine Clay Treated by Biomass Silica. KSCE Journal of Civil Engineering, KSCE, 22(11), 4316-4326. https://doi.org/10.1007/s12205-018-1294-X.

31. Gupta, C., Sharma, R.K., 2014. Influence of Marble Dust, Fly Ash and Beach Sand on Sub- 
grade Characteristics of Expansive Soils. International Conference on Advances in Engineering and Technology, 13-18.

32. James, J., Pandian, P.K., 2016. Industrial Wastes as Auxiliary Additives to Cement/lime Stabilization of Soils. Adv. Civ. Eng., 1-17.

33. Esmaeilpour, S.N., Abbasali T.G., Mohammadreza, K.T., Asskar, J.C., 2019. Improvement of the Engineering Behavior of Sand-clay Mixtures Using Kenaf Fiber Reinforcement. Transportation Geotechnics, 19, 1-8. https://doi.org/10.1016/j.trgeo.2019.01. 004.

34. Keerthi, Y., Divya Kanthi, P., Tejaswi, N., Shyam Chamberlin, K., Satyanarayana, B., 2013. Stabilization of Clayey Soil Using Cement Kiln Waste. Int. J. Adv. Struct. Geotech. Eng., 2(2), 77-81.

35. Abbaspour, M., Aflaki, E., Nejad, F.M., 2019. Reuse of Waste Tire Textile Fibers as Soil Reinforcement. Journal of cleaner production, 207, 1059-1071.

36. Liu, Y., Chang, C.W., Namdar, A., She, Y., Lin, C.H., Yuan, X., Yang, Q., 2019. Stabilization of Expansive Soil Using Cementing Material from Rice Husk Ash and Calcium Carbide Residue. Construction and Building Materials, 221, 1-11.

37. Shah, S.A.R., Mahmood, Z., Nisar, A., Aamir, M., Farid, A., Waseem, M., 2020. Compaction Performance Analysis of Alum Sludge Waste Modified Soil. Construction and Building Materials, 230, 116953.

38. Taki, K., Choudhary, S., Gupta, S., Kumar, M., 2020. Enhancement of Geotechnical Properties of Municipal Sewage Sludge for Sustainable Utilization as Engineering Construction Material. Journal of Cleaner Production, 251, 119-723.

39. Chauhan, M.S., Mittal, S., Mohanty, B., 2008. Performance Evaluation of Silty Sand Subgrade Reinforced with Fly Ash and Fibre, Journal of Geotextiles and Geomembranes, 26(5), 429-435.

40. Akbulut, S., Arasan, S., Kalkan, E., 2007. Modification of Clayey Soils Using Scrap Tire Rubber and Synthetic Fibers, Applied Clay Science, 38, 23-32.
41. Demir, İ., Başpınar, M.S., Görhan, G., Kahraman, E., 2008. Mermer Tozu ve Atıklarının Kullanım Alanlarının Araştırılması, 6. Mermer ve Doğal taş Sempozyumu, 26-27 Haziran, Afyonkarahisar.

42. Ghazavi, M., Roustaie, M., 2010. The Influence of Freeze-thaw Cycles on the Unconfined Compressive Strength of Fiberreinforced Clay, Cold Regions Science and Technology, 61, 125-131.

43. Güllü, H., Hazirbaba, K., 2010. California Bearing Ratio Improvement and Freeze-thaw Performance of Fine-grained Soils Treated with Geofiber and Synthetic Fluid. Cold Regions Science and Technology, 63, 50-60.

44. Jafari, M., Esna-Ashari, M., 2012. Effect of Waste Tire Cord Reinforcement on Unconfined Compressive Strength of Lime Stabilized Clayey Soil Under Freeze-Thaw Condition, Cold Regions Science and Technology, 82, 21-29.

45. Yarbaşı, N., 2016. Atık Lastik Parçalarıyla Güçlendirilmiş Killi Zeminlerin DonmaÇözülme Davranışı, Pamukkale Üniversitesi Mühendislik Bilimleri Dergisi, 22(6), 559-562.

46. Kalkan, E., 2009. Effects of Silica Fume on The Geotechnical Properties of Fine-Grained Soils Exposed to Freeze and Thaw, Cold Regions Science and Technology, 58(3), 130-135.

47. Kalkan, E., 2013. Preparation of Scrap Tires Rubber Fiber-Silica Fume Mixtures for Modification of Clayey Soils, Applied Clay Science, 80-81, 117-125.

48. Zaimoğlu, A.Ş., 2010. Freezing-thawing Behavior of Fine-grained Soils Reinforced with Polypropylene Fibers, Cold Regions Science and Technology, 60, 63-65.

49. Zorluer, I., Demirbas, A., 2013. Use of Marble Dust and Fly Ash in Stabilization of Base Material, Science and Engineering of Composite Materials, 20(1), 47-55.

50. Zaimoğlu, A.Ş., Hattatoğlu, F., Akbulut, R.K., 2013. Yüke Maruz İnce Taneli Zeminlerin Donma-çözülme Davranışı. Pamukkale Üniversitesi Mühendislik Bilimleri Dergisi, 19(3), 117-121.

51.Zaimoğlu, A.Ş., Akbulut, R.K., Arasan, S., 2015. Effect of Freze-thaw Cycles on Strength 
Behavior of Compacted Chicken Quill Clay Composite in Undrained Loading. Journal of Natural Fibers, 13(3), 299-308.

52.Zaimoğlu, A.Ş., Calik, Y., Akbulut, R.K., Yetimoglu, T., 2016. A Study on Freeze-thaw Behavior of Randomly Distributed Fiberreinforced Soil. Periodica Polytechnica: Civil Engineering, 60(1), 3-9.

53. Andersland, O.B., Ladanyi, B., 1994. An Introduction to Frozen Ground Engineering. Second Edition. The American Society of Civil Engineering, John Wiley \& Sons Inc., New Jersey.

54. Simonsen, E., Isacsson, U., 1999. Thaw Weakening of Pavement Structures in Cold Regions. Cold Regions Science and Technology, 29, 135-151.

55. Wang, D., Ma, W., Niu, Y., Chang, X., Wen, Z., 2007. Effects of Cyclic Freezing and Thawing on Mechanical Properties of QighaiTibet Clay. Cold Region and Science Technology, 48, 34-43.

56. Qi, J., Ma, W., Song, C., 2008. Influence of Freeze-thaw on Engineering Properties of a Silty Soil. Cold Region Science and Technology, 53, 397-404.

57. Tester, R.E., Gaskin, P.N., 1996. Effect of Fines Content on Frost Heave. Canadian Geotechnical Journal, 33, 678-680.

58. Hermansson, A., 2002. Laboratory and Field Testing on Rate of Frost Heave Versus Heat Extraction. Cold Region and Science Technology, 38, 137-151.

59. Konrad, J.M., Lemieux, N., 2005. Influence of Fines on Frost Heave Characteristics of a Wellgraded Base-course Material. Canadian Geotechnical Journal, 42, 515-527.

60. Hui, B., Ping, H., 2009. Frost Heave and Dry Density Changes During Cyclic Freeze-thaw of Silty Clay. Permafrost and Periglacial Processes, 20, 65-70.

61. Rempel, A., 2010. Frost Heave. Journal of Glaciology, 56(200), 1122-1128.

62. TS 1500, 2000: İnşaat Mühendisliğinde Zeminlerin Sınıflandırılması, Türk Standartları Enstitüsü. Ankara.

63. Hazirbaba, K., Zhang, Y., Hulsey J.L., 2011. Evaluation of Temperature and Freeze-thaw Effects on Excess Pore Pressure Generation of
Fine-grained Soils. Soil Dynamics and Earthquake Engineering, 31, 372-384.

64. Liu, J., Wang, T., Tian, Y., 2010. Experimental Study of the Dynamic Properties of Cementand lime- Modified Clay Soils Subjected to Freeze-thaw Cycles. Cold Regions Science and Technology, 61, 29-33.

65. TS 1900-2, 2006: İnşaat Mühendisliğinde Zemin Laboratuvar Deneyleri-Bölüm 2: Mekanik Özelliklerin Tayini. Türk Standartları Enstitüsü, Ankara. 
